\title{
FTIR spectroscopy and X-ray powder diffraction characterization of microcrystalline cellulose obtained from alfa fibers
}

\author{
D. Trache ${ }^{1}$, K. Khimeche ${ }^{1}$, A. Donnot ${ }^{2}$, and R. Benelmir ${ }^{2}$ \\ ${ }^{1}$ Chimie appliquée, Ecole Militaire Polytechnique E.M.P., B.P 17 Bordj-El-Bahri, Alger, Algérie \\ ${ }^{2}$ LERMAB, Faculté des Sciences et Techniques, Université de Lorraine, 54506 Vandœuvre-les-Nancy, France
}

\begin{abstract}
Many cereal straws have been used as raw materials for the preparation of microcrystalline cellulose (MCC). These raw materials were gradually replaced with wood products; nevertheless about $10 \%$ of the world overall pulp production is obtained from non-wood raw material. The main interest in pulp made from straw is that it provides excellent fibres for different industries with special properties, and that it is the major available source of fibrous raw material in some geographical areas.

The aim of the present work was to characterize microcrystalline cellulose prepared from alfa fibers using the hydrolysis process. The products obtained are characterized with FTIR spectroscopy and X-ray powder diffraction.

As a result, FTIR spectroscopy is an appropriate technique for studying changes occurred by any chemical treatment. The spectrum of alfa grass stems shows the presence of lignin and hemicelluloses. However, the cellulose spectrum indicates that the extraction of lignin and hemicellulose was effective. The X-ray analysis indicates that the microcrystalline cellulose is more crystalline than the source material.
\end{abstract}

\section{Introduction}

Stipa tenacissima L. (esparto grass or alfa grass) is a perennial tussock grass widely distributed in semi-arid ecosystems of the southern and western Mediterranean basin, mainly in the Maghreb. It occupies in North Africa about 7 million ha and it belongs to the graminacies family and grows to a height of about $1 \mathrm{~m}$ [1-3].

At present, cellulose is the most abundant polymer available worldwide and a representative renewable resource. Microcrystalline cellulose has been used for many years in different industries like cosmetics, plastics, food, pharmaceuticals, etc. MCC is obtained in industrial scale from wood and cotton cellulose using dilute mineral acids [4].

In the present work, the MCC was prepared from esparto grass. The characterisations were done using FTIR spectroscopy and X-ray diffraction.

\section{Experimental}

Alfa grass fibres were collected from the Saïda area, in Algeria. The extraction of cellulose from Alfa grass was occurred using the method given elsewhere [5]. Microcrystalline cellulose was prepared using cellulose sample obtained from esparto grass by hydrochloric acid hydrolysis [6].

\section{Results and discussion}

FTIR spectroscopy is an appropriate technique for studying changes occurred by any chemical treatment. The spectrum of alfa grass stems shows the presence of lignin and hemicelluloses. However, the cellulose spectrum indicates that the extraction of lignin and hemicellulose was efficient. In addition, the spectra of extracted cellulose and the prepared microcrystalline cellulose samples are identical to that of commercial one. In these spectra, all characteristic absorption peaks of cellulose are present.

The X-ray analysis indicates that the microcrystalline cellulose is more crystalline than the source material. The increase in the crystallite sizes for the prepared cellulose particles might be associated with a reduction in the corresponding amorphous region. If the amorphous domains of cellulose are attacked during the hydrolysis treatment, chain scission and peeling reactions can occur, which reduce the total amount of amorphous region and therefore increase the crystallite sizes of microcrystalline cellulose particles. Consequently, crystallinity indexes increased with increasing crystallite sizes because the crystallites surface corresponding to amorphous region decreased. 


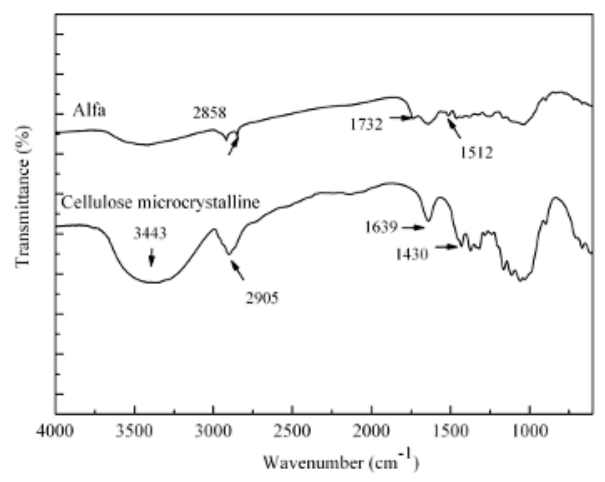

Figure 1. FTIR spectra of alfa grass fibres and cellulose microcrystalline derived from it.

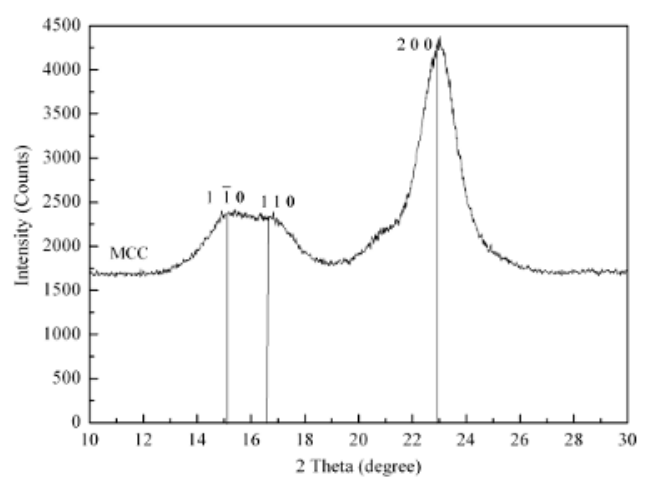

Figure 2. X-ray diffraction patterns of prepared cellulose microcrystalline.

\section{References}

1. A. Bessadok, S. Marais, F. Gouanve, L. Colasse, I. Zimmerlin, S. Roudesli, M. Metayer, Compo. Sci. Technol. 67685 (2007)

2. P. García-Fayos, M.Gasque, Acta Oecol. 30276 (2006)

3. H. Nadji, P.N. Diouf, A. Benaboura, Y. Bedard, B. Riedl, T. Stevanovic, Bioresour. Technol. 1003585 (2009)

4. A.M. Adel, H.Z. Abd El-Wahab, A.A. Ibrahim, M.T. Al-Shemy, Bioresour. Technol. 1014446 (2010)

5. E.M. Maafi, F. Malek, L. Tighzert, P. Dony, Journal of Polymer Environment 18638 (2010)

6. M. Hanna, G. Blby, V. Miladinove, US Patent 6 ,228, 213 (2001) 